stress those perched songs they find most effective. This is no more novel than showing that individuals with several innate feeding strategies stress the one that results in the most food. It would be novel to show that nonbreeding females in nature purposefully guide male song development, but West and King do not do so.

STEPHEN I. ROTHSTEIN JOSEPH C. ORTEGA ADRIAN O'LOGHLEN Department of Biological Sciences, University of California, Santa Barbara, California 93106, USA

WEST AND KING REPLY-When Rothstein et al. consult the chronology of published work on female social influence in cowbirds ${ }^{1(-1)}$, they will find answers to many of their questions.

Two inaccuracies need to be clarified. First, North Carolina cowbirds are on breeding habitats in March and April, court in March and lay eggs in late April; 30-50-day-old juveniles are collected at our laboratory in June. The reference on winter habitats cited by Rothstein et al. includes no records from North Carolina and conflicts with other reports for the species $^{18}$. We regret that our report ${ }^{1} \mathrm{did}$ not state that all birds were from North Carolina. Intraspecific differences in vocal behavour in cowbirds are potentially relevant to understanding the influence of ecology on ontogeny ${ }^{19-21}$.

Second, Rothstein et al. misunderstand us when they introduce the topic of flight whistles. We wrote that copulatory postures and wing strokes both occur while the male's song is in progress. We use the criterion of temporal co-occurrence to restrict analysis to objectively proximate effects. If females adopted copulatory postures or wing stroked during a flight whistle, we would define it as a response to that signal. We did test a flight whistle (song number 8 in experiment 1 ): no female responded.

We have also tested Rothstein's hypothesis that a flight whistle serves as a final check on a male's identity before mating. Field recordings of four local and two distant $(240 \mathrm{~km})$ distinct types of flight whistle, and six local and distant song types, from breeding M.a. obscurus males in Texas were played to five females from the same site using the methods described'. The females responded to a mean of 9 per cent (range 3-16 per cent) of the flight whistles and 55 per cent (range 37-87 per cent) of the songs. No evidence of flight whistle selectivity was present; the most distant flight whistle received the most responses (16 per cent).

We do not dispute that cowbirds in the western United States may behave differently; we predict geographical differences on empirical grounds ${ }^{2 !}$. But the relevance of the remarks to the issues at hand is tenuous. Our report describes a behavi- oural means by which non-singing females could affect vocal behaviour in males. Multiple lines of evidence led to the postulation of social shaping, including data from North Carolina populations suggesting that females benefited from such behaviour in terms of enhanced ability to assess males' singing ability, and that males benefited by configuring maximally effective repertoires ${ }^{13.17}$. The data on wing stroking provide a concrete example of how shaping could occur. The data may not be persuasive to those who consider studies of animals in captivity artefactual. But, for those who share our interest in understanding social and cognitive capacities underlying vocal learning, the data introduce a new level of inquiry - visual experience - and a new form of vocal learning - non-imitative social shaping findings with widespread implications for behavioural and neurobiological studies of songbirds.

Nevertheless, we have not ignored the issue of relevance to natural conditions. We studied the rate and stages of vocal development in captive and wild North Carolina males, finding no differences ${ }^{15}$. Eastzer $^{2}$ also used our laboratory data on geographical differences in playback responsiveness to explain structural variation in vocal behaviour in eight field populations in two subspecies.

Rothstein et al. also question whether wing stroking produced enduring effects. Such an effect is not necessary to show ontogenetic influences ${ }^{23}$. We can add, however, that the wing-stroke songs tested were the most potent and most

1. West, M.J. \& King, A.P. Nature 334, 244-246 (1988). 2. King, A.P. \& West, M.J. Nature 305, 704-706 (1983). 3. West, M.J. \& King, A.P. Z. Tierpsychol. 70, 225 (1985).

4. West, M.J., King, A.P. \& Eastzer, D.H. Am. Scient. 69 56-66 (1981)

5. Rothstein, S.I., Yokel, D.A. \& Fleischer, R.C. Anim. Behav. 36, 73-86 (1988)

6. Rothstein, S.l., Yokel, D.A. \& Fieischer, R.C. Curr. Ornith. 3, 127-185

7. Dolbeer, R.A. J. Field Ornith. 53, 28-46 (1982)

8. Wilson, E.O. Sociobiology, The New Synthesis (Belknap. Cambridge, Massachusetts, 1975).

9. Eastzer, D.H., King, A.P. \& West, M.J. Anim. Behav. 33 30-39 (1985).

10. West, M.J., King, A.P. \& Harrocks, T.H. J. comp. Psychol. 97. 327-337 (1983)

11. King, A.P. \& West, M.J. Learning and Motivation 15 , 441-458 (1984)

12. West, M.J. \& King, A.P. Ethology 70. 225-235 (1985).

13. West, M.J. \& King, A.P. J comp. Psychol. 100, 296 (1986)

14. King, A.P. \& West, M.J. Devl Psychobiol. 20, 177 (1987).

15. King, A.P. \& West, M.J. Anim. Behav. 36, 1575 (1988).

16. West, M.J. \& King, A.P. Devl Psychobiol. 21, 543 (1988).

17. King, A.P. \& West, M.J. J. comp. Psychol. $1031-6$ (1989).

18. Potter, E.F., Parnell, J.F. \& Teulings, R.P. Birds of the Carolinas (Univ. North Carolina Press. Chapel Hill, 1980)

19. King, A.P., West, M.J. \& Eastzer, D. H. Ethology 72, 8998 (1986)

20. West, M.J. \& King, A.P. Nebr. Symp. Motiv. 35, 51-89 (1988).

21. King, A.P. \& West, M.J. in Contemporary Issues in Com parative Psychology (ed. Dewsbury, D.A.) (Sinauer. Sunderland, 1989)

22. Eastzer, D.H. Thesis, Univ. North Carolina (1988)

23. Gould, S.J. Ontogeny and Phylogeny (Belknap, Cambridge, 1977).

24. Webster's Ninth New Collegiate Dictionary (MerriamWebster, Springfield, 1984).

25. Smith, W.J. The Behavior of Communicating, An Ethological Approach (Harvard. Cambridge, 1977).

26. Morgan, C.L. An Introduction to Comparative Psychology (Scott, London, 1894) frequently produced song type during the breeding season for the six males on which data were available. Furthermore, differences in the vocal phenotypes of males raised with females first appear in late autumn suggesting that long-term deprivation from males is not needed to direct a male's attention to female behaviour ${ }^{15}$.

Finally, whether or not the wing stroke is a display is controversial ${ }^{8.24 .25}$. The novelty of the work is that it advances research on birdsong into new sensory and social domains. To suggest that novelty cannot be claimed until we show that females "purposefully guide" behaviour represents a retreat from modern principles of behavioural analysis. With C. Lloyd Morgan's 1894 canon $^{26}$ as a guide, we aspire only to the investigation of the role of experience in changing behaviour.

MEREDITH J. WEST

Department of Psychology,

University of North Carolina,

Chapel Hill, North Carolina 27599, USA

ANDREW P. KING

Department of Psychology,

Duke University,

Durham, North Carolina 27706, USA

\section{First come}

SIR-Carilli, van Gorkum and Stocke' have recently shown that neutral atomic hydrogen observed in both absorption and emission extends from NGC 3067 in the direction of the QSO 3C232 and apparently completely envelopes it. The obvious conclusion, which they never directly make, is that this provides direct evidence that the two objects are physically associated despite the fact that their redshifts are very different.

What these authors do not point out, though they do reference the paper in another connection, is that this quasargalaxy pair was one of four pairs shown in 1971 by myself and colleagues ${ }^{2}$ to be much closer to bright galaxies than would be expected by chance among all 47 of the $3 \mathrm{C}$ and $3 \mathrm{CR}$ quasars identified at that time. This result was farther confirmed by Monte Carlo calculations made by Kippenhahn and de Vries?.

Thus we concluded in 1971 that those pairs were physically associated. The new result' clearly supports this conclusion and adds further to the unpopular but real evidence that the redshifts of some quasars, at least, are not measures of their distances.

\section{Center for Astrophysics and} GEOFFREY BURBIDGE

\section{Space Sciences,}

University of California, San Diego,

La Jolla, California 92093, USA

1. Carilli, C.L., van Gorkum, J.H. \& Stocke, J.T. Nature 338 134-136 (1989)

. Burbidge, E.M., Burbidge, G.R., Solomon, P.M. \& Strittmatter, P.A. Astrophys. J. 170, 233-240 (1971)

3. Kippenhahn, R. \& de Vries, H.L. Astrophys. space Sci. 26 131-135 (1974) 